\title{
Inpatient Admissions and Costs Associated with Persistent Use of Dalfampridine Extended-Release in Multiple Sclerosis: A Claims Database Analysis
}

\author{
Amy Guo, PhD; Alexander Niyazov, PharmD, MPH; Dendy Macaulay, PhD; Emi Terasawa, PhD;
} Luke Schmerold, BS; Eric Q. Wu, PhD; and Stephen Krieger, MD

\begin{abstract}
BACKGROUND: While the clinical benefits of dalfampridine extendedrelease (D-ER) have been established in patients with multiple sclerosis (MS) through multiple clinical trials, there is limited real-world data on D-ER use, in particular the persistent use of D-ER, and associated acute care resource utilization and costs.
\end{abstract}

OBJECTIVE: To examine the real-world association of D-ER use and inpatient admissions and costs among patients with MS.

METHODS: This study was a retrospective observational claims analysis of the MarketScan database (April 2009-March 2014). Eligible patients consisted of adult enrollees aged 18-64 years who had (a) 12 months of continuous private plan enrollment preceding (baseline) and following (follow-up) the first D-ER claim; (b) $\geq 2$ MS diagnosis codes with $\geq 1$ during the baseline period; (c) $\geq 2$ consecutive D-ER claims; and (d) no alternate gait-impairing etiologies during the baseline and follow-up periods. Patients were separated into $2 \mathrm{D}$-ER cohorts in the main analysis: persistent ( $\geq 360$ days of D-ER supply) and nonpersistent ( $<360$ days of supply) users. Sensitivity analyses were conducted, examining additional breakdowns of days of supply within the nonpersistent cohort. Inpatient admissions (all-cause and MS-related) and health care expenditures were calculated and compared between the cohorts during follow-up using Wilcoxon ranksum and chi-square tests. Regression models were conducted, controlling for age, sex, MS relapses, comorbidities, disease-modifying therapy use, and other baseline factors, including inpatient admissions and costs.

RESULTS: Of 1,598 eligible patients, 719 (45.0\%) were persistent D-ER users, and $879(55.0 \%)$ were nonpersistent D-ER users. The 2 cohorts had similar demographic and clinical characteristics, with mean (SD) ages of $51.0(8.4)$ and 50.6 (8.6) years and were $71.3 \%$ and $66.6 \%$ female, respectively. Compared with nonpersistent D-ER use, persistent D-ER use was associated with lower odds of all-cause inpatient admissions $(\mathrm{OR}=0.58$, $P=0.010)$ and MS-related inpatient admissions $(0 R=0.50, P=0.004)$. Persistent use was also associated with lower inpatient expenditures for all-cause admissions ( $\$ 669$ vs. $\$ 1,515, P=0.002$ ) and MS-related admissions ( $\$ 388$ vs. $\$ 891, P=0.008$ ).

CONCLUSIONS: Persistent D-ER use was associated with significantly lower rates of all-cause and MS-related inpatient admissions and costs.

J Manag Care Spec Pharm. 2017;23(7):771-80

Copyright $\odot 2017$, Academy of Managed Care Pharmacy. All rights reserved.

\section{What is already known about this subject}

Patients with multiple sclerosis (MS) experience substantial medical costs and disability because of the chronic and complex nature of the disease.

Walking difficulty has been reported by some patients with MS to be the most important bodily function affected by the disease. Dalfampridine extended-release (D-ER) is indicated to improve walking in patients with MS as demonstrated by an increase in walking speed.

\section{What this study adds}

This study describes the association between persistent use of D-ER and inpatient admissions and costs in a real-world MS patient population.

Persistent D-ER use was associated with lower rates of inpatient hospitalization and lower costs, in both unadjusted and baselineadjusted comparisons.

The most differences were found between persistent D-ER users and those with less than a 180-day supply of D-ER in a year.

$\mathrm{M}$ ultiple sclerosis (MS) is a chronic and disabling immune-mediated condition of the central nervous system, with a variable and intermittent disease course in most cases, but eventually leading to progressive neurological and functional decline. ${ }^{1}$ MS was estimated to affect around 400,000 people in the United States and approximately 2.3 million worldwide in 2013. ${ }^{2}$ Symptoms typically appear between the ages of 20 and 40 years, with diagnoses being rare after the age of $50 ., 34$

Walking has been reported to be the most important bodily function affected by MS. In a 2008 survey of MS patients, 70\% of the respondents reported that walking difficulty was the most challenging aspect of their condition. ${ }^{5,6}$ In other studies, $85 \%$ of patients with MS experienced walking-related mobility challenges. ${ }^{7}$ This functional impairment can have broad implications for patients' daily lives and can result in direct economic consequences. ${ }^{8-11}$ Costs may be even higher when considering indirect costs such as work loss and disability. For example, $79 \%$ of patients experienced negative employment effects. ${ }^{12}$ 


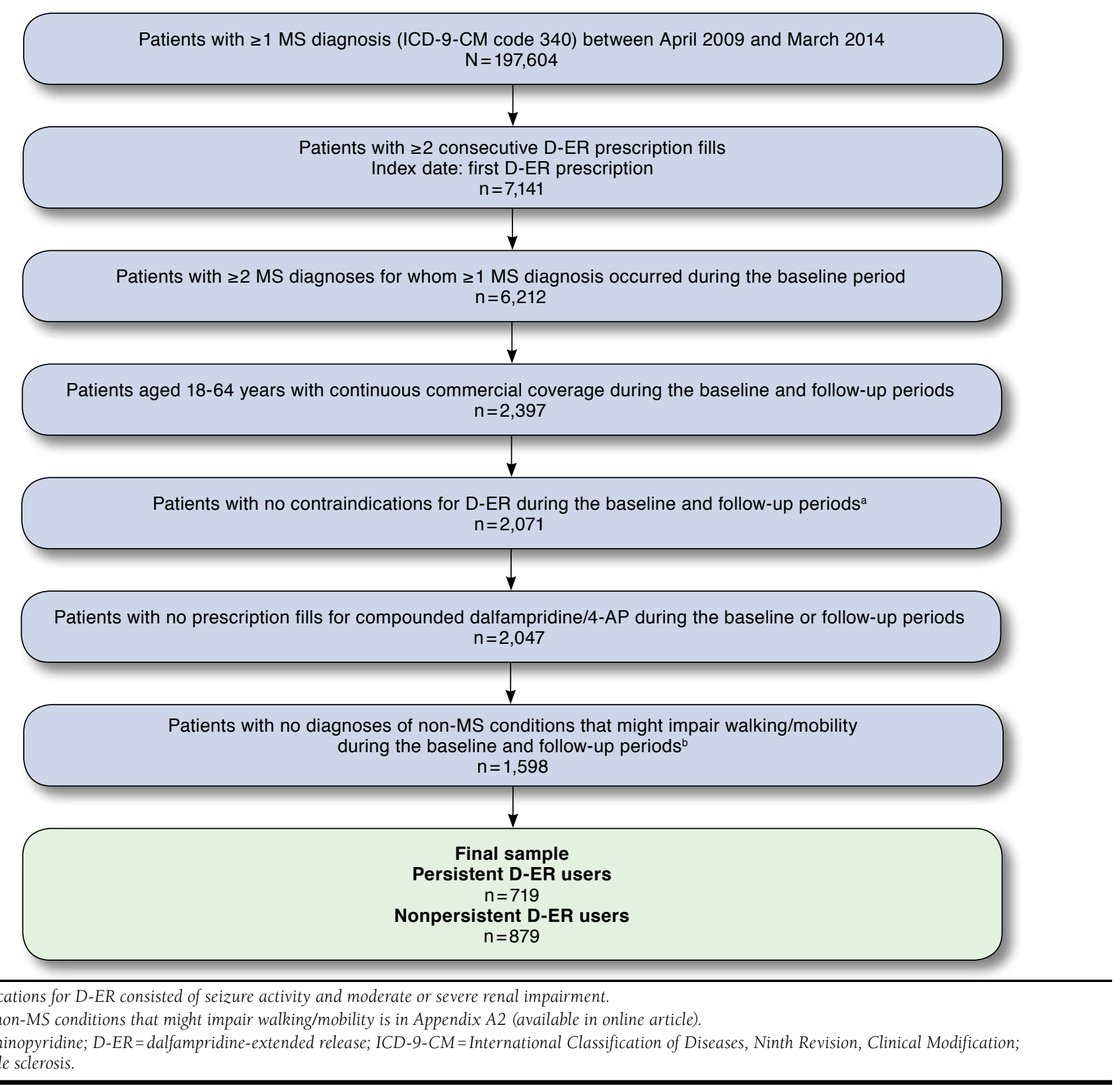

Dalfampridine extended-release (D-ER; known as prolonged-release fampridine in Europe and as fampridine modified-or sustained-release elsewhere) $10 \mathrm{mg}$ tablets twice daily was the first symptomatic therapy approved by the U.S. Food and Drug Administration (January 2010) to improve walking ability in MS patients. ${ }^{13}$ In phase III trials, MS patients on D-ER showed improved walking ability over a 14-week observational period. ${ }^{14-16}$ Currently, however, there is limited real-world data on the longer-term effects of D-ER on walking ability and patient outcomes. An exception to this is a recent claims database study that found that the majority of patients initiated on D-ER were adherent to treatment and that patients on D-ER experienced fewer physician and other outpatient visits related to walking impairment than patients not treated with D-ER. ${ }^{17}$

In our study, we add to the literature on real-world use of D-ER and associated patient outcomes. In particular, we 
assessed the association between persistent versus nonpersistent use of D-ER and inpatient admissions and costs across D-ER users from a real-world MS patient population. These acute care outcomes are highly relevant for this population, given the broad and pronounced health implications that walking impairment can have for patients. These implications include increased fall risk, decline in cardiovascular and musculoskeletal health, and poorer mental health, which can precipitate acute medical events. In addition, these outcomes are highly relevant to payers for whom they can be important cost drivers.

\section{Methods}

\section{Data Source and Study Design}

A retrospective analysis was conducted using the Truven Health Analytics MarketScan Commercial Claims and Encounters (CCAE) Database. The CCAE database captures medical benefits, enrollment history, and claims for medical and pharmacy services for all enrolled employees and their dependents.

All data in this study were de-identified by Truven Health Analytics and comply with the patient confidentiality requirements of the Health Insurance Portability and Accountability Act. The data were exempt from individual institutional review board approval.

\section{Study Sample}

The study period was April 2009-March 2014, and over 74.2 million covered lives were included. The start date was selected to maximize capture of patients on D-ER and allowed for a 12-month baseline period before the launch of D-ER in March 2010. Cost information in the data represents actual payments rather than the charged amounts, enabling description of realworld costs experienced across payers.

Patient inclusion criteria were as follows: (a) 12 months of continuous private health plan enrollment preceding (baseline period) and following (follow-up period) their first D-ER claim (index date); (b) $\geq 2$ MS diagnosis codes (International Classification of Diseases, Ninth Revision, Clinical Modification code 340) with $\geq 1$ MS diagnosis occurring during the baseline period; (c) aged 18-64 years at the index date; and (d) $\geq 2$ consecutive D-ER claims (i.e., a supply gap $\leq 30$ days between the first 2 claims; Figure 1).

Patients were excluded if they exhibited any of the following characteristics during the baseline or follow-up periods: (a) experienced a contraindication for D-ER use per the prescribing information (Appendix Al, available in online article); (b) had a gait-impairing etiology other than MS (i.e., brain neoplasm/abscess, Parkinson's disease, cerebral palsy, muscular dystrophy, stroke, tendonitis/tendon injury, spinal cord injury, and paralysis/hemiplegia); or (c) had a diagnosis code indicating they were wheelchair bound (Appendix A2). Patients were also excluded if they were covered by a capitated health plan, since their payment amounts may not have accurately reflected usage patterns (by virtue of the capitation system).

Patients were grouped into 2 mutually exclusive cohorts: persistent D-ER users (having $\geq 360$ days of D-ER supply during the follow-up period) and nonpersistent D-ER users (having <360 days of D-ER supply during the follow-up period). Among the nonpersistent cohort, the mean (standard deviation [SD]) days of D-ER supply was 187 (93), while the median (interquartile range) was 180 (90-270). Sensitivity analyses were also conducted, examining additional breakdowns of days of supply within the nonpersistent cohort to provide greater granularity on the relationship between D-ER persistence and the outcomes.

\section{Patient Characteristics and Study Outcomes}

A wide range of patient characteristics were collected and assessed for each study cohort during the 12-month baseline period. These characteristics included demographics; MS disease characteristics (number of inferred MS relapses, walking difficulties, falls and fractures, and MS symptoms); the Charlson Comorbidity Index (CCI) ${ }^{18,19}$ comorbidities; previous treatments for mobility and MS-related issues; health resource utilization (HRU); and expenditures. MS relapses were inferred using a widely used algorithm developed by Ollendorf et al. $(2002)^{20}$ and modified by Halpern et al. (2011). ${ }^{21}$ The diagnosis and procedure codes and treatments used to identify the baseline characteristics are listed in Appendix A.

The following outcomes were assessed for each study cohort over the 12-month follow-up period: all-cause and MS-related inpatient admissions and all-cause and MS-related inpatient expenditures. For the inpatient admission outcomes, the percentage of patients with any admission was examined, as well as the number of admissions per patient. For the expenditure outcomes, insurer and patient contributions were included in the calculations. Expenditures were converted to 2014 U.S. dollars, using the medical care component of the Consumer Price Index.

\section{Statistical Analyses}

Baseline characteristics, including HRU and expenditures, were summarized for the cohorts using descriptive statistics. Differences between the cohorts were assessed using Wilcoxon rank-sum tests for continuous variables and chi-square tests for categorical variables.

The study outcomes were summarized and compared for the cohorts over the follow-up period, using unadjusted and baseline-adjusted analyses. For the unadjusted analyses, comparisons were performed using Wilcoxon rank-sum and chi-square tests for continuous and categorical variables, respectively. For the adjusted analyses, regressions analyses were used that controlled for a comprehensive set of baseline characteristics, which could represent potential confounders. 


\section{Inpatient Admissions and Costs Associated with Persistent Use of Dalfampridine Extended-Release in Multiple Sclerosis: A Claims Database Analysis}

\section{TABLE 1 Baseline Characteristics}

\begin{tabular}{|c|c|c|c|c|c|}
\hline & \multicolumn{2}{|c|}{$\begin{array}{l}\text { Persistent D-ER Users } \\
\qquad \mathrm{n}=719\end{array}$} & \multicolumn{2}{|c|}{$\begin{array}{l}\text { Nonpersistent D-ER Users } \\
\qquad \mathbf{n}=879\end{array}$} & $P$ Value $^{\mathrm{a}}$ \\
\hline \multicolumn{6}{|l|}{ Demographics and insurance } \\
\hline Age at the index date (years), mean (SD) & 51.0 & $(8.4)$ & 50.6 & $(8.6)$ & 0.422 \\
\hline Female, n (\%) & 513 & $(71.3)$ & 585 & $(66.6)$ & $0.040^{\mathrm{b}}$ \\
\hline \multicolumn{5}{|l|}{ Region of residence, $\mathrm{n}(\%)$} & 0.086 \\
\hline Northeast & 196 & $(27.3)$ & 228 & $(25.9)$ & \\
\hline North Central & 218 & $(30.3)$ & 273 & $(31.1)$ & \\
\hline South & 183 & $(25.5)$ & 257 & $(29.2)$ & \\
\hline West & 122 & $(17.0)$ & 118 & $(13.4)$ & \\
\hline Unknown & 0 & $(0.0)$ & 3 & $(0.3)$ & \\
\hline \multicolumn{5}{|l|}{ Insurance type, n (\%) } & 0.624 \\
\hline Comprehensive & 35 & $(4.9)$ & 47 & $(5.3)$ & \\
\hline Exclusive provider organization & 16 & $(2.2)$ & 12 & $(1.4)$ & \\
\hline Noncapitated point of service & 67 & $(9.3)$ & 76 & $(8.6)$ & \\
\hline Preferred provider organization & 470 & $(65.4)$ & 589 & $(67.0)$ & \\
\hline Consumer-directed health care & 46 & $(6.4)$ & 45 & $(5.1)$ & \\
\hline Other & 85 & $(11.8)$ & 110 & $(12.5)$ & \\
\hline \multicolumn{6}{|l|}{ MS characteristics } \\
\hline Number of MS relapses, mean (SD) & 0.77 & $(2.19)$ & 0.75 & $(2.07)$ & 0.618 \\
\hline \multicolumn{6}{|l|}{ MS symptoms, n (\%) } \\
\hline Muscle weakness & 72 & $(10.0)$ & 78 & $(8.9)$ & 0.437 \\
\hline Spasms (muscle) & 67 & $(9.3)$ & 78 & $(8.9)$ & 0.758 \\
\hline Disturbances of skin sensation & 48 & $(6.7)$ & 75 & $(8.5)$ & 0.166 \\
\hline Malaise and fatigue & 122 & $(17.0)$ & 185 & $(21.0)$ & $0.040^{\mathrm{b}}$ \\
\hline Dizziness/giddiness/vertiginous syndromes & 33 & $(4.6)$ & 50 & $(5.7)$ & 0.325 \\
\hline Vision problems & 44 & $(6.1)$ & 78 & $(8.9)$ & $0.039^{b}$ \\
\hline Visual disturbances (including optic neuritis) & 29 & $(4.0)$ & 56 & $(6.4)$ & $0.038^{b}$ \\
\hline Use of DMTs, n (\%) & 570 & $(79.3)$ & 677 & $(77.0)$ & 0.278 \\
\hline Interferon beta-la & 216 & $(30.0)$ & 273 & $(31.1)$ & 0.661 \\
\hline Interferon beta- $1 \mathrm{~b}$ & 77 & $(10.7)$ & 81 & $(9.2)$ & 0.319 \\
\hline Glatiramer acetate & 203 & $(28.2)$ & 227 & $(25.8)$ & 0.280 \\
\hline Natalizumab & 103 & $(14.3)$ & 133 & $(15.1)$ & 0.652 \\
\hline Other DMTs ${ }^{\mathrm{c}}$ & 25 & $(3.5)$ & 27 & $(3.1)$ & 0.650 \\
\hline Walking and/or movement difficulties, $\mathrm{n}(\%)$ & 204 & $(28.4)$ & 262 & $(29.8)$ & 0.530 \\
\hline Difficulty in walking & 42 & $(5.8)$ & 49 & $(5.6)$ & 0.819 \\
\hline Abnormal gait & 152 & $(21.1)$ & 195 & $(22.2)$ & 0.615 \\
\hline Lack of coordination & 25 & $(3.5)$ & 43 & $(4.9)$ & 0.163 \\
\hline Abnormal involuntary movements & 38 & $(5.3)$ & 39 & $(4.4)$ & 0.431 \\
\hline Antitremor and/or antispasticity medication use, $\mathrm{n}(\%)$ & 358 & $(49.8)$ & 428 & $(48.7)$ & 0.662 \\
\hline Anticonvulsant medication use, $\mathrm{n}(\%)$ & 90 & $(12.5)$ & 111 & $(12.6)$ & 0.947 \\
\hline Any falls or fractures resulting in medical visits, $\mathrm{n}(\%)$ & 125 & $(17.4)$ & 144 & $(16.4)$ & 0.594 \\
\hline Accidental falls & 13 & $(1.8)$ & 17 & $(1.9)$ & 0.854 \\
\hline Traumatic fractures & 40 & $(5.6)$ & 44 & $(5.0)$ & 0.619 \\
\hline Nontraumatic fractures & 92 & $(12.8)$ & 103 & $(11.7)$ & 0.513 \\
\hline Purchase of a wheelchair or wheelchair accessory, n (\%) & 47 & $(6.5)$ & 58 & $(6.6)$ & 0.961 \\
\hline \multicolumn{6}{|l|}{ Comorbidities $^{\mathrm{d}}$} \\
\hline CCI, mean (SD) & 0.36 & $(0.79)$ & 0.32 & $(0.70)$ & 0.470 \\
\hline \multicolumn{6}{|l|}{ Comorbid condidtions, n (\%) } \\
\hline Depression & 59 & $(8.2)$ & 123 & $(14.0)$ & $<0.001^{\mathrm{e}}$ \\
\hline Dyslipidemia & 174 & $(24.2)$ & 236 & $(26.8)$ & 0.228 \\
\hline Thyroid disease & 87 & $(12.1)$ & 95 & $(10.8)$ & 0.418 \\
\hline Hypercholesterolemia & 176 & $(24.5)$ & 239 & $(27.2)$ & 0.219 \\
\hline Arthritis & 338 & $(47.0)$ & 413 & $(47.0)$ & 0.992 \\
\hline Mild to moderate diabetes & 39 & $(5.4)$ & 56 & $(6.4)$ & 0.426 \\
\hline Cardiovascular disease (including hypertension) & 184 & $(25.6)$ & 241 & $(27.4)$ & 0.411 \\
\hline
\end{tabular}




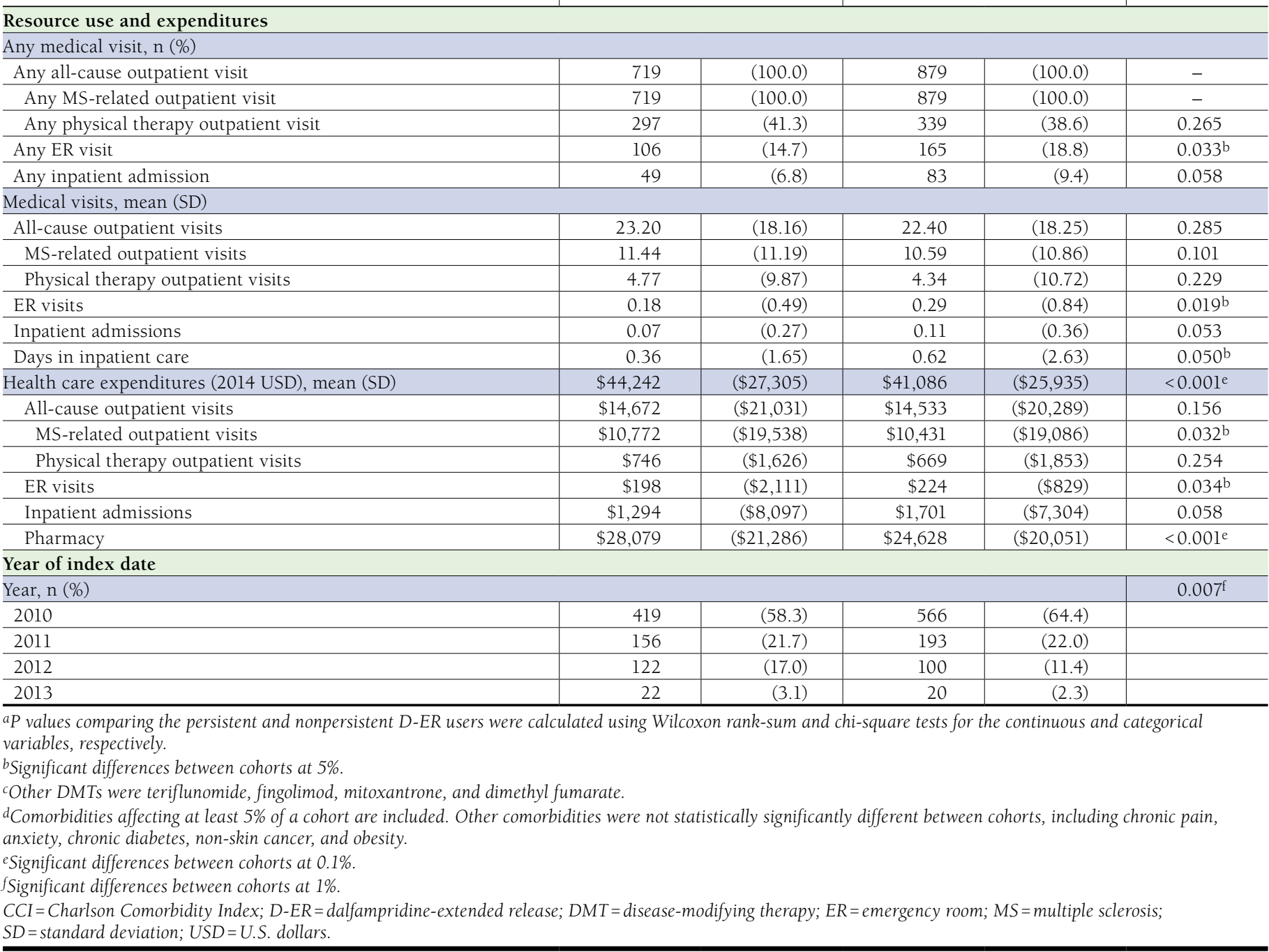

These characteristics included age at index date, sex, U.S. region of residence, index year (i.e., the calendar year of the index date), number of MS relapses, malaise and fatigue, vision problems, any use of disease-modifying therapies (DMTs), CCI, depression, any antitremor and/or antispasticity medication use, any anticonvulsant medication use, any walking and/ or movement difficulties, any falls or fractures resulting in medical visits, and the number of emergency room (ER) visits during the baseline period. In addition, the adjusted analyses for inpatient admissions controlled for the number of inpatient admissions during the baseline period. Similarly, the adjusted analysis for inpatient expenditures additionally controlled for total all-cause expenditures during the baseline period.
For the adjusted regression analyses, functional forms for the models were selected according to the outcome examined. Logistic regressions were used to examine the binary outcomes (e.g., any inpatient admission), and the odds ratios (ORs) were reported. For the count outcomes (e.g., number of inpatient admissions), analyses were conducted using negative binomial regressions with the incidence rate ratios (IRRs) reported. Inpatient expenditures were analyzed using generalized linear models with a Tweedie distribution (due to their rightward skew), ${ }^{22}$ and the mean difference between the cohorts was reported. For each model, the predicted value was calculated for the patient with average characteristic levels in the overall sample and compared under 2 scenarios-with and without 
TABLE 2 Health Care Resource Utilization and Expenditures for Persistent Versus Nonpersistent D-ER Users over Follow-up Period

\begin{tabular}{|c|c|c|c|c|c|}
\hline & \multicolumn{2}{|c|}{$\begin{array}{l}\begin{array}{l}\text { Persistent D-ER Users } \\
\text { a }\end{array} \\
\qquad=719\end{array}$} & \multicolumn{2}{|c|}{$\begin{array}{l}\text { Nonpersistent D-ER Users }{ }^{a} \\
\qquad \mathrm{n}=879\end{array}$} & $P$ Value $^{\mathrm{b}}$ \\
\hline \multicolumn{6}{|l|}{ Inpatient admissions } \\
\hline Any all-cause inpatient admission, $\mathrm{n}(\%)$ & 39 & (5.4) & 82 & $(9.3)$ & $0.003^{c}$ \\
\hline Any MS-related inpatient admission & 29 & $(4.0)$ & 72 & $(8.2)$ & $<0.001^{\mathrm{d}}$ \\
\hline All-cause inpatient admissions, mean (SD) & 0.06 & $(0.27)$ & 0.12 & $(0.41)$ & $0.003^{c}$ \\
\hline MS-related inpatient admissions & 0.04 & $(0.22)$ & 0.10 & $(0.39)$ & $<0.001^{\mathrm{d}}$ \\
\hline \multicolumn{6}{|l|}{ Health care resource expenditures (2014 USD) } \\
\hline All-cause inpatient expenditures, mean (SD) & $\$ 1,387$ & $(\$ 8,826)$ & $\$ 3,019$ & $(\$ 15,751)$ & $0.003^{c}$ \\
\hline MS-related inpatient expenditures & $\$ 937$ & $(\$ 7,401)$ & $\$ 1,580$ & $(\$ 7,442)$ & $<0.001^{\mathrm{d}}$ \\
\hline \multicolumn{6}{|c|}{$\begin{array}{l}\text { aPersistent D-ER users were defined as patients with at least } 360 \text { days of D-ER supply. Nonpersistent D-ER u } \\
D \text {-ER supply. } \\
\text { bP values comparing the persistent and nonpersistent D-ER users were calculated using Wilcoxon rank-sum ar } \\
\text { variables, respectively. } \\
\text { cSignificant differences between the cohorts at } 1 \% \text {. } \\
\text { dSignificant differences between the cohorts at } 0.1 \% \text {. } \\
D \text {-ER=dalfampridine-extended release; } M S=\text { multiple sclerosis; } S D=\text { standard deviation; USD=U.S. dollars. }\end{array}$} \\
\hline
\end{tabular}

persistent D-ER use-to assess association of persistent D-ER use with the patient outcomes.

In addition to the main analyses, a sensitivity analysis was conducted comparing inpatient admissions and expenditures of the persistent D-ER cohort with subgroups of the nonpersistent D-ER user cohort to better understand trends associated with varying levels of nonpersistence. Four subgroups were examined consisting of the following: (1) D-ER supply of $<90$ days; (2) D-ER supply $\geq 90$ and $<180$ days; (3) D-ER supply $\geq 180$ and $<270$ days; and (4) D-ER supply $\geq 270$ and $<360$ days. Comparisons conducted mirrored those of the main analyses, as previously described.

All statistical analyses were performed using SAS software version 9.3 (SAS Institute, Cary, NC).

\section{Results}

\section{Patient and Disease Characteristics}

A total of 1,598 patients met the inclusion criteria and were included in the study. Of these, 719 were persistent D-ER users, and 879 were nonpersistent D-ER users (Figure 1). The 2 cohorts were similar for many of the baseline characteristics assessed. These characteristics included age, region of residence, and insurance type, along with the following MS-related characteristics: number of MS relapses; MS symptoms (i.e., muscle weakness, spasms, disturbances of skin sensation, and dizziness); use of DMTs; recorded walking and movement difficulties; use of antitremor/antispasticity medications; use of anticonvulsant medications; any falls or fractures; and purchase of a wheelchair or wheelchair accessory. Other similarities between the cohorts included various comorbidities (i.e., dyslipidemia, thyroid disease, hypercholesterolemia, arthritis, mild to moderate diabetes, and cardiovascular disease), as well as outpatient and physical therapy visits.

Significant differences between the cohorts were observed for the following set of baseline characteristics: sex, malaise and fatigue, visual problems including visual disturbances, depression, ER visits, ER costs, days in inpatient care, and select expenditure variables. For some of these characteristics, such as vision problems and visual disturbances, the numeric difference between the cohorts was quite small (less than 3\%). Among the expenditure variables, baseline overall expenditures were significantly higher among the persistent D-ER users compared with the nonpersistent users ( $\$ 44,242$ vs. $\$ 41,086$, $P<0.001)$. A similar trend was observed for MS-related outpatient visit costs $(\$ 10,772$ vs. $\$ 10,431$ for persistent and nonpersistent $D$-ER users, respectively, $P=0.032$ ) and pharmacy costs ( $\$ 28,079$ vs. $\$ 24,628$, respectively, $P<0.001$; Table 1 ).

\section{Inpatient Admissions}

During the follow-up period, fewer persistent D-ER users had inpatient admissions than nonpersistent D-ER users (5.4\% vs. 9.3\%, $P=0.003$; Table 2). A similar trend was also observed for MS-related inpatient admissions (4.0\% vs. $8.2 \%$ for persistent vs. nonpersistent $D$-ER users, respectively, $P<0.001$ ). Rates of per-patient inpatient admissions were also consistent with these patterns, with lower rates observed for persistent versus nonpersistent D-ER users (all-cause: 0.06 vs. 0.12 admissions per patient per year, respectively, $P=0.003$; MS-related: 0.04 vs. 0.10 , respectively, $P<0.001$; Tables 1 and 2). Results of the sensitivity analysis, comparing the persistent D-ER cohort with subgroups of the nonpersistent D-ER cohort, were consistent with the main analysis and showed lower persistence levels 
TABLE 3 Adjusted Comparison of Health Care Resource Utilization and Expenditures for Persistent Versus Nonpersistent D-ER Usersa

\begin{tabular}{|c|c|c|c|c|}
\hline & \multicolumn{4}{|c|}{ Adjusted Analysis: 12-Month Follow-up } \\
\hline & $\begin{array}{c}\text { Comparative Estimate } \\
{[\text { A] vs. [B] }}\end{array}$ & $P$ Value & $\begin{array}{c}\text { Persistent D-ER Users } \\
{[\mathrm{A}]}\end{array}$ & $\begin{array}{c}\text { Nonpersistent D-ER Users } \\
{[\mathrm{B}]}\end{array}$ \\
\hline Any inpatient admission & Odds ratio & & \multicolumn{2}{|c|}{ Adjusted mean probability (\%) } \\
\hline Any all-cause inpatient admission & 0.58 & $0.010^{\mathrm{b}}$ & 4.6 & 7.6 \\
\hline Any MS-related inpatient admission & 0.50 & $0.004^{b}$ & 3.3 & 6.4 \\
\hline Number of inpatient admissions & Incidence rate ratio & & \multicolumn{2}{|c|}{ Adjusted mean incidence rate ( 12 months) } \\
\hline Number of all-cause inpatient admissions & 0.60 & $0.012^{c}$ & 0.05 & 0.09 \\
\hline Number of MS-related inpatient admission & 0.48 & $0.002^{b}$ & 0.04 & 0.07 \\
\hline Health care resource expenditures (2014 USD) & Mean difference & & \multicolumn{2}{|c|}{ Adjusted mean expenditures (12 months) } \\
\hline All-cause inpatient expenditures & $-\$ 846$ & $0.002^{b}$ & $\$ 669$ & $\$ 1,515$ \\
\hline MS-related inpatient expenditures & $-\$ 503$ & $0.008^{b}$ & $\$ 388$ & $\$ 891$ \\
\hline
\end{tabular}

being associated with higher resource use (Appendix B, available in online article).

After adjusting for baseline characteristics, the previously mentioned trends in inpatient admission outcomes persisted, with the odds of all-cause hospitalization being significantly lower for persistent $D$-ER users relative to nonpersistent D-ER users (adjusted OR=0.58, P=0.010; Table 3). This corresponded to an adjusted probability of having an allcause inpatient admission during the follow-up year of $4.6 \%$ with persistent D-ER use versus $7.6 \%$ with nonpersistent use. Similarly, the odds of having an MS-related inpatient admission during the follow-up period for persistent D-ER users were half of those of the nonpersistent D-ER users (adjusted $\mathrm{OR}=0.50, P=0.004)$; the adjusted probability for persistent versus nonpersistent use was $3.3 \%$ versus $6.4 \%$, respectively. In adjusted analyses that compared the cohorts' all-cause and MS-related inpatient admissions, persistent D-ER users had lower rates of admissions than nonpersistent users (IRRs of $0.60, P=0.012$, and $0.48, P=0.002$, respectively; Table 3 ).

The results of the sensitivity analyses were consistent with the main analysis, with lower persistence levels being associated with higher resource use (Table 4). For all-cause inpatient admissions, the adjusted mean probability of having an admission was $9.8 \%, 8.9 \%, 6.5 \%$, and $6.4 \%$ for the nonpersistent subgroups with D-ER supply of $<90$ days, $\geq 90$ and $<180$ days, $\geq 180$ and $<270$ days, and $\geq 270$ and $<360$ days, respectively. By contrast, patients in the persistent cohort had an adjusted mean probability of an inpatient admission of $4.5 \%$. The regression results showed a significant difference between the 2 nonpersistent subgroups with lowest persistence (i.e., $<90$ days D-ER supply and $\geq 90$ and $<180$ days of D-ER supply) compared with the persistent cohort $(P=0.019$ and $P=0.008$, respectively). Although the other 2 nonpersistent subgroups displayed numerically higher adjusted mean probabilities for an inpatient admission than the persistent cohort (i.e., $6.5 \%$ and $6.4 \%$ vs. $4.5 \%$ ), significance was not detected. This may, however, reflect inadequate sample size and power to detect a difference.

\section{Inpatient Expenditures}

Inpatient expenditures were significantly lower for the persistent D-ER users relative to the nonpersistent D-ER users in the follow-up period. Specifically, mean all-cause inpatient expenditures were $\$ 1,387$ per year for persistent users versus $\$ 3,019$ per year for nonpersistent users $(P=0.003$; Table 2$)$. For MS-related inpatient admissions, these expenditures were $\$ 937$ per year versus $\$ 1,580$, respectively $(P<0.001)$. In the sensitivity analysis comparing inpatient expenditures of the persistent D-ER cohort with subgroups of the nonpersistent D-ER cohort, the greatest differences again appeared between the persistent D-ER cohort and nonpersistent patients in the lowest persistence subgroups (Appendix B).

Significant differences in inpatient expenditures remained for the 2 cohorts after adjusting for baseline characteristics. For all-cause inpatient admissions, the adjusted mean expenditure per patient was $\$ 669$ for persistent users versus $\$ 1,515$ for nonpersistent users, a difference of $\$ 846$ ( $P=0.002$; Table 3). Similar results were observed for MS-related inpatient expenditures (Table 3). In the sensitivity analysis with adjustments for baseline characteristics, greater persistence was again associated with lower expenditures (Table 4). The subgroups with $<90$ days and $\geq 90$ and $<180$ days D-ER supply had significantly higher all-cause (mean differences of $\$ 1,415, P=0.012$, and $\$ 1,120, P=0.004$, respectively) and MS-related (mean 


\section{Inpatient Admissions and Costs Associated with Persistent Use of Dalfampridine Extended-Release in Multiple Sclerosis: A Claims Database Analysis}

TABLE 4 Sensitivity Analysis: Adjusted Comparison of Health Care Resource Utilization and Expenditures for Persistent Users Versus Subgroups of Nonpersistent D-ER Users ${ }^{\mathrm{a}}$

\begin{tabular}{|c|c|c|c|}
\hline & \multicolumn{3}{|c|}{ Adjusted Analysis: 12-Month Follow-up } \\
\hline & Comparative Estimate & $P$ Value & D-ER Users \\
\hline Any inpatient admission & Odds ratio & & $\begin{array}{l}\text { Adjusted mean } \\
\text { probability (\%) }\end{array}$ \\
\hline \multicolumn{4}{|l|}{ Any all-cause inpatient admission } \\
\hline D-ER supply $<90$ days & 2.28 & $0.019^{b}$ & 9.8 \\
\hline 90 days $\leq$ D-ER supply $<180$ days & 2.05 & $0.008^{\mathrm{c}}$ & 8.9 \\
\hline 180 days $\leq$ D-ER supply $<270$ days & 1.45 & 0.243 & 6.5 \\
\hline 270 days $\leq$ D-ER supply $<360$ days & 1.44 & 0.208 & 6.4 \\
\hline Persistent D-ER users & Reference & - & 4.5 \\
\hline \multicolumn{4}{|l|}{ Any MS-related inpatient admission } \\
\hline D-ER supply $<90$ days & 2.57 & $0.014^{b}$ & 8.1 \\
\hline 90 days $\leq$ D-ER supply $<180$ days & 2.26 & $0.006^{c}$ & 7.2 \\
\hline 180 days $\leq$ D-ER supply $<270$ days & 1.70 & 0.126 & 5.5 \\
\hline 270 days $\leq$ D-ER supply $<360$ days & 1.71 & 0.086 & 5.5 \\
\hline Persistent D-ER users & Reference & - & 3.3 \\
\hline Number of inpatient admissions & Incidence rate ratio & & $\begin{array}{c}\text { Adjusted mean incidence } \\
\text { rate (12 months) }\end{array}$ \\
\hline \multicolumn{4}{|c|}{ Number of all-cause inpatient admissions } \\
\hline D-ER supply $<90$ days & 2.45 & $0.005^{c}$ & 0.13 \\
\hline 90 days $\leq$ D-ER supply $<180$ days & 1.88 & $0.015^{b}$ & 0.10 \\
\hline 180 days $\leq$ D-ER supply $<270$ days & 1.35 & 0.321 & 0.07 \\
\hline 270 days $\leq$ D-ER supply $<360$ days & 1.40 & 0.219 & 0.07 \\
\hline Persistent D-ER users & Reference & - & 0.05 \\
\hline \multicolumn{4}{|c|}{ Number of MS-related inpatient admissions } \\
\hline D-ER supply $<90$ days & 2.82 & $0.004^{c}$ & 0.10 \\
\hline 90 days $\leq$ D-ER supply $<180$ days & 2.29 & $0.004^{c}$ & 0.08 \\
\hline 180 days $\leq$ D-ER supply $<270$ days & 1.75 & 0.091 & 0.06 \\
\hline 270 days $\leq$ D-ER supply $<360$ days & 1.80 & $0.048^{b}$ & 0.06 \\
\hline Persistent D-ER users & Reference & - & \begin{tabular}{|c|}
0.04 \\
\end{tabular} \\
\hline Health care resource expenditures & Mean difference & & $\begin{array}{c}\text { Adjusted mean } \\
\text { expenditures (12 months) }\end{array}$ \\
\hline \multicolumn{4}{|c|}{ All-cause inpatient expenditures (2014 USD) } \\
\hline D-ER supply $<90$ days & 1,415 & $0.012^{b}$ & $\$ 2,087$ \\
\hline 90 days $\leq$ D-ER supply $<180$ days & 1,120 & $0.004^{c}$ & $\$ 1,792$ \\
\hline 180 days $\leq$ D-ER supply $<270$ days & 451 & 0.209 & $\$ 1,123$ \\
\hline 270 days $\leq$ D-ER supply $<360$ days & 623 & 0.068 & $\$ 1,295$ \\
\hline Persistent D-ER users & Reference & - & $\$ 672$ \\
\hline \multicolumn{4}{|c|}{ MS-related inpatient expenditures (2014 USD) } \\
\hline D-ER supply $<90$ days & $\$ 741$ & $0.045^{\mathrm{b}}$ & $\$ 1,131$ \\
\hline 90 days $\leq$ D-ER supply $<180$ days & $\$ 598$ & $0.025^{\mathrm{b}}$ & $\$ 988$ \\
\hline 180 days $\leq$ D-ER supply $<270$ days & $\$ 416$ & 0.128 & $\$ 806$ \\
\hline 270 days $\leq$ D-ER supply $<360$ days & $\$ 362$ & 0.129 & $\$ 752$ \\
\hline Persistent D-ER users & Reference & - & $\$ 390$ \\
\hline \multicolumn{4}{|c|}{$\begin{array}{l}\text { aThe adjusted analyses of the health care resource utilization and expenditure outcomes were conducted bas } \\
\text { study sample. } \\
\text { bSignificance for the comparative estimates at } 5 \% \text {. } \\
\text { cSignificance for the comparative estimates at } 1 \% \text {. } \\
D \text {-ER=dalfampridine-extended release; ER=emergency room; MS = multiple sclerosis; USD=U.S. dollars. }\end{array}$} \\
\hline
\end{tabular}

differences of $\$ 741, P=0.045$, and $\$ 598, P=0.025)$ inpatient expenditures than persistent users. Although the other nonpersistent subgroups had numerically higher expenditures than the persistent cohort, significance was not detected. Similar to the inpatient admission analysis, this may reflect inadequate sample size and power to detect a difference. 


\section{Discussion}

This retrospective claims database analysis evaluated the association between persistent D-ER use and inpatient admissions and expenditures among patients with MS in a real-world setting. The study's findings show that persistent D-ER use is associated with significantly lower inpatient resource utilization and costs, even after controlling for differences in baseline characteristics that could influence these outcomes. These results were further reinforced by sensitivity analyses that revealed a general trend of greater D-ER persistence levels being associated with lower inpatient resource utilization and costs.

These results are consistent with previous literature indicating that impaired walking/abnormal gait in MS patients is associated with higher economic costs. ${ }^{8,10,11}$ One study found that the cost of MS nearly doubled in patients with gait abnormality relative to the overall MS patient population $(\$ 48,361$ $[\$ 55,472]$ vs. $\$ 26,520$ [\$38,478], respectively, for mean [SD] annual per patient charges in a 2011 sample of MS patients with private insurance in the United States). ${ }^{11}$ In a 2009 real-world cross-sectional doctor and patient survey in the European Union, increasing severity of mobility issues was associated with significantly higher frequency of hospitalization due to MS $(P<0.001) .{ }^{8}$ In addition, patients with longer walking times during the timed 25-foot walk (indicating greater walking impairment) were significantly more likely to require primary care consultations $(P=0.004)$, urologist visits $(P=0.006)$, and time spent with occupational therapists $(P=0.010){ }^{8}$ Recent claims database analyses evaluating walking-attributable hospitalizations and outpatient visits (to neurologists and physical/ occupational therapy) among D-ER adherent and nonadherent patients with MS found that the D-ER adherent cohort experienced significantly less HRU over a 12-month period than nonadherent users. ${ }^{17}$

Although causality cannot be established from these findings, it is possible that walking impairment, with its broad implications for patient health, well-being, and social functioning, may be a direct contributor to, and an indirect marker of, acute care needs. Persistent use of D-ER to improve ambulatory function may have additional real-world consequences beyond the direct effect on mobility as suggested by the decrease in accompanying inpatient admissions and costs.

\section{Limitations}

This study is subject to several limitations, some of which are inherent to claims analyses and observational studies. First, claims data may be subject to coding errors and incompleteness and do not directly capture certain clinical assessment. ${ }^{23-25}$ For example, walking and/or movement difficulties may have been undercoded or miscoded within claims, which could have resulted in underreporting. Second, although claims data capture patients' prescription filling behavior, it is not known whether patients actually took their medications; use must be inferred from patient prescription fills. Third, as with any observational study, despite efforts to extensively control for differences between the cohorts, unobserved confounders may exist. These confounders may include unobserved differences in disease severity between the cohorts that could affect the outcomes, as well as unobserved differences in responsiveness or resistance to D-ER treatment that could influence patient persistence.

Despite the limitations, claims data remain a valuable resource for examining real-world treatment trends and outcomes, with their findings strongly representative of clinical practice. ${ }^{26,27}$ In addition, they provide important and relevant information on real-world clinical and economic outcomes for MS patients, their families, and employers.

\section{Conclusions}

This study showed that persistent use of D-ER is associated with lower inpatient admissions and costs. This association remains even after controlling for differences in patient baseline characteristics.

\section{Authors}

AMY GUO, PhD, and ALEXANDER NIYAZOV, PharmD, MPH, Acorda Therapeutics, Ardsley, New York. DENDY MACAULAY, PhD; EMI TERASAWA, PhD; and LUKE SCHMEROLD, BS, Analysis Group, New York, New York. ERIC Q. WU, PhD, Analysis Group, Boston, Massachusetts, and STEPHEN KRIEGER, MD, Icahn School of Medicine at Mount Sinai, New York, New York.

AUTHOR CORRESPONDENCE: Amy Guo, PhD, Acorda Therapeutics, 420 Saw Mill River Rd., Ardsley, New York, NY 10502.Tel.: 914.326.5836; E-mail: ami_guo3@yahoo.com.

\section{DISCLOSURES}

Funding for this research and medical writing assistance was provided by Acorda Therapeutics. The study sponsor was involved in all stages of the study research and manuscript preparation. Guo and Niyazov were employees of Acorda Therapeutics at the time of this study and may own stock/stock options. Wu, Macaulay, Terasawa, and Schmerold are employees of Analysis Group, which received consultancy fees from Acorda Therapeutics for this project. Krieger was a consultant for Acorda Therapeutics for this project and has the following additional financial interests to report: consulting/advisory board work with Bayer, Biogen, EMD Serono, Novartis, Genentech, Genzyme, and Teva.

Study concept and design were contributed by Guo, Niyazov, Macaulay, and $\mathrm{Wu}$. Macaulay, Terasawa, Schmerold, and $\mathrm{Wu}$ helped prepare the data, and data interpretation was performed by Krieger, Guo, Niyazov, and Macaulay, along with Terasawa and $\mathrm{Wu}$. The manuscript was written by Terasawa and Schmerold, along with Macaulay, and revised by all the authors.

A portion of the current research was presented in poster format at the 2106 American Academy of Neurology Annual Meeting, which took place in Vancouver, BC, Canada, on April 15-21, 2016. 


\section{ACKNOWLEDGMENTS}

Medical writing assistance was provided by Ana Bozas, PhD, and Shelley Batts, PhD, employees of Analysis Group, and funded by Acorda Therapeutics.

\section{REFERENCES}

1. Dutta R, Trapp BD. Relapsing and progressive forms of multiple sclerosis: insights from pathology. Curr Opin Neurol. 2014;27(3):271-78.

2. Browne P, Chandraratna D, Angood C, et al. Atlas of multiple sclerosis 2013: A growing global problem with widespread inequity. Neurology. 2014:83(11):1022-1024.

3. Confavreux C, Vukusic S. Age at disability milestones in multiple sclerosis. Brain. 2006;129(Pt 3):595-605.

4. Poser S, Raun NE, Poser W. Age at onset, initial symptomatology and the course of multiple sclerosis. Acta Neurol Scand. 2009;66(3):355-362.

5. Harris Interactive. Experiences with multiple sclerosis (MS): perspectives of people with MS and MS care partners [poll]. March 25, 2008.

6. LaRocca NG. Impact of walking impairment in multiple sclerosis. Patient. 2011;4(3):189-201

7. Hemmett L, Holmes J, Barnes M, Russell N. What drives quality of life in multiple sclerosis? 2JM. 2004;97(10):671-676.

8. Pike J, Jones E, Rajagopalan K, Piercy J, Anderson P. Social and economic burden of walking and mobility problems in multiple sclerosis. BMC Neurol. 2012;12:94.

9. Raggi A, Covelli V, Schiavolin S, Scaratti C, Leonardi M, Willems M. Work-related problems in multiple sclerosis: a literature review on its associates and determinants. Disabil Rehabil. 2016;38(10):936-44.

10. Prescott JD, Factor S, Pill M, Levi GW. Descriptive analysis of the direct medical costs of multiple sclerosis in 2004 using administrative claims in a large nationwide database. J Manag Care Pharm. 2007;13(1):44-52. Available at: http://www.jmcp.org/doi/abs/10.18553/jmcp.2007.13.1.44.

11. Carroll CA, Fairman KA, Lage MJ. Updated cost-of-care estimates for commercially insured patients with multiple sclerosis: retrospective observational analysis of medical and pharmacy claims data. BMC Health Serv Res. 2014;14(1):286.

12. Harris Interactive. Talking and learning to keep mobile: a survey about difficulty walking among people with MS [poll]. Commissioned by Acorda Therapeutics and the National MS Society. July 29, 2011.

13. Ampyra (dalfampridine), extended release tablets, for oral use. Acorda Therapeutics. 2010. Available at: https://www.accessdata.fda.gov/drugsatfda_ docs/label/2010/022250s000lbl.pdf. Accessed May 16, 2017.
14. Applebee A, Goodman AD, Mayadev AS, et al. Effects of dalfampridine extended-release tablets on 6-minute walk distance in patients with multiple sclerosis: a post hoc analysis of a double-blind, placebo-controlled trial. Clin Ther. 2015;37(12):2780-87.

15. Goodman AD, Bethoux F, Brown TR, et al. Long-term safety and efficacy of dalfampridine for walking impairment in patients with multiple sclerosis: results of open-label extensions of two phase 3 clinical trials. Mult Scler. 2015;21(10):1322-31.

16. Goodman AD, Brown TR, Krupp LB, et al. Sustained-release oral fampridine in multiple sclerosis: a randomised, double-blind, controlled trial. Lancet. 2009;373(9665):732-38.

17. Guo A, Grabner M, Palli SR, et al. Treatment patterns and health care resource utilization associated with dalfampridine extended release in multiple sclerosis: a retrospective claims database analysis. Clinicoecon Outcomes Res. 2016;8:177-86.

18. Charlson ME, Pompei P, Ales KL, MacKenzie CR. A new method of classifying prognostic comorbidity in longitudinal studies: development and validation. J Chronic Dis. 1987;40(5):373-83.

19. Quan H, Sundararajan V, Halfon P, et al. Coding algorithms and for defining comorbidities data in ICD-9-CM and ICD-10 administrative data. Med Care. 2005;43(11):1130-39.

20. Ollendorf DA, Jilinskaia E, Oleen-Burkey M. Clinical and economic impact of glatiramer acetate versus beta interferon therapy among patients with multiple sclerosis in a managed care population. J Manag Care Pharm. 2002;8(6):469-76. Available at: http://www.jmcp.org/doi/10.18553/ jmcp.2002.8.6.469.

21. Halpern R, Agarwal S, Borton L, Oneacre K, Lopez-Bresnahan MV. Adherence and persistence among multiple sclerosis patients after one immunomodulatory therapy failure: retrospective claims analysis. Adv Ther. 2011;28(9):761-75.

22. Frees EW, Jin X, Lin X. Actuarial applications of multivariate two-part regression models. Ann Actuar Sci. 2013;7(2):258-87.

23. O'Malley KJ, Cook KF, Price MD, Wildes KR, Hurdle JF, Ashton CM. Measuring diagnoses: ICD code accuracy. Health Serv Res. 2005; 40(5 Pt 2):1620-39.

24. Peabody JW, Luck J, Jain S, Bertenthal D, Glassman P. Assessing the accuracy of administrative data in health information systems. Med Care. 2004;42(11):1066-72.

25. Roche N, Reddel H, Martin R, et al. Quality standards for real-world research. Focus on observational database studies of comparative effectiveness. Ann Am Thorac Soc. 2014;11(Suppl 2):S99-S104.

26. Garrison LP, Neumann PJ, Erickson P, Marshall D, Mullins CD. Using real-world data for coverage and payment decisions: the ISPOR Real-World Data Task Force report. Value Health. 2007;10(5):326-35.

27. Motheral BR, Fairman KA. The use of claims databases for outcomes research: rationale, challenges, and strategies. Clin Ther. 1997;19(2):346-66. 


\section{Inpatient Admissions and Costs Associated with Persistent Use of Dalfampridine Extended-Release in Multiple Sclerosis: A Claims Database Analysis}

\section{APPENDIX A Diagnostic and Drug Codes Used in Study Selection and Design}

Type

1. Contraindications for Dalfampridine

ICD-9-CM

2. Non-MS Conditions that Impair Mobility ICD-9-CM

\section{MS Symptoms}

ICD-9-CM

\section{MS Comorbidities}

ICD-9-CM

\section{Walking/Movement Impairment} ICD-9-CM
Condition

Codes

History of seizures

Moderate or severe renal impairment

345.xx, 780.3x

580.81, 584.xx-588.xx, 590.0-590.3, 590.8, 590.9,

599.7, 791.0, 794.4, 39.95, 54.98, 55.69, V45.1,

V56.0-V56.2, V56.31, V56.32, V56.8

\begin{tabular}{|l|}
\hline Brain neoplasm/abscess \\
\hline Parkinson's disease \\
\hline Cerebral palsy \\
\hline Muscular dystrophy \\
\hline Stroke \\
\hline Tendonitis/tendon injury \\
\hline Spinal cord injury \\
\hline Paralysis/hemiplegia \\
\hline Long-term wheelchair use \\
\hline
\end{tabular}

191.xx, 198.3, 225.0, 237.5, 239.6, 324.0, 324.9, V12.41

$332 . x$

333.7, 343.xx

$359.0,359.1, \mathrm{~V} 46.3$

430.x-432.x, 433.x1, 434.xl, 436, 438.xx

726.6-726.9, 727.xx, 891.2x, 893.2x, 894.2x

806.x, 952.x

342.x, 344.0x, 344.1x, 344.3x

V46.3

\begin{tabular}{|l|}
\hline Muscular weakness \\
\hline Spasms (muscle) \\
\hline Disturbances of skin sensation \\
\hline Visual disturbances (including optic neuritis) \\
\hline Vision loss \\
\hline Blurred vision \\
\hline Diplopia \\
\hline Nystagmus \\
\hline Internuclear ophthalmoplegia \\
\hline Dizziness/giddiness/vertiginous syndromes \\
\hline Malaise and fatigue \\
\hline
\end{tabular}

\subsection{7}

$781.0,728.85$

782.0

$341.0,377.3 \mathrm{x}$

369.xx

368.8

368.2

$379.5 \mathrm{x}$

378.86

386.xx, 780.4

780.7

\begin{tabular}{|l|}
\hline Depression \\
\hline Chronic pain \\
\hline Anxiety \\
\hline Urinary incontinence \\
\hline Urinary tract infection \\
\hline Dyslipidemia \\
\hline Hypercholesterolemia \\
\hline Thyroid disease \\
\hline Arthritis \\
\hline Diabetes mellitus \\
\hline Non-skin cancer \\
\hline $\begin{array}{l}\text { History of cardiovascular disease (including } \\
\text { hypertension) }\end{array}$ \\
\hline Hypertension \\
\hline Obesity \\
\hline
\end{tabular}

$296.2,296.3,311$

$338.0,338.29,338.4,780.96$

$293.84,300.0 x, 309.24$

788.3

590.xx, 595.xx, 597.xx, 599.xx

$272.0-272.5$

272.0

193.xx, 240.xx-246.xx

274.x, 710.xx-716.xx, 719.xx-721.xx, 725.xx-729.xx

$250 . x x$

140.xx-209.xx (excluding 172.x, 173.x)

389.91, 401.xx-405.xx , 414.0, 414.2, 414.3, 428.0,

428.3, 428.4, 440.xx-449.xx, V17.49

401.xx-404.xx, 642.0x-642.2x, 642.7x

278.xx, V85.35-V85.39, V85.4

Walking/movement difficulties

Difficulty in walking

Abnormal gait

Lack of coordination

Abnormal involuntary movements

719.7

781.2

781.3

781.0

Falls or fractures resulting in medical visits

Accidental falls

Traumatic fractures

Non-traumatic fractures

E880.x-E888.x

800.xx-829.x

733.xx 


\section{Inpatient Admissions and Costs Associated with Persistent Use of Dalfampridine Extended-Release in Multiple Sclerosis: A Claims Database Analysis}

\section{APPENDIX A Diagnostic and Drug Codes Used in Study Selection and Design (continued)}

Type and Purpose

Drug Name

6. Medications Used in Study

Corticosteroids for inferred MS relapses

Noncorticosteroid therapies for inferred

MS relapses

Antispasticity and antitremor medications

Anticonvulsants

DMTs

Intravenous methylprednisolone, corticotrophin, oral methylprednisolone, prednisone, prednisolone, dexamethasone, and betamethasone

Adrenocorticotropic hormone (ACTH), plasmapheresis

Baclofen, intrathecal baclofen, tizanidine, gabapentin, dantrolene, Sativex (oromucosal spray), botulinum toxin, isoniazid, hydroxyzine, propranolol, primidone, acetazolamide, buspirone, and clonazepam

Gabapentin, carbamazepine, oxcarbazepine, lamotrigine, pregabalin, phenytoin

Teriflunomide, interferon beta-la, interferon beta-lb, glatiramer acetate, fingolimod, mitoxantrone, dimethyl fumarate, natalizumab

\begin{tabular}{l|l}
\hline \multicolumn{1}{l}{ Type } & \multicolumn{1}{c}{ Codes } \\
\hline \multicolumn{1}{l}{ Physical Therapy Outpatient Visits Codes } \\
\hline CPT-4 & $\begin{array}{l}97001,97002,97003,97004,97110,97112,97113,97116,97124,97139,97140,97504,97760,97530, \\
97799\end{array}$ \\
\hline Revenue codes & $0420,0421,0422,0423,0424,0429,0977$ \\
\hline Provider type & 850 \\
\hline
\end{tabular}

CPT-4 = Current Procedural Terminology, 4th edition; DMTs = disease-modifying therapies; ICD-9-CM = International Classification of Diseases, Ninth Revision, Clinical Modification. 
Inpatient Admissions and Costs Associated with Persistent Use of Dalfampridine

Extended-Release in Multiple Sclerosis: A Claims Database Analysis

\section{APPENDIX B Sensitivity Analysis: Health Care Resource Utilization and Expenditures for Persistent Versus} Nonpersistent D-ER Users over Follow-up Period

\begin{tabular}{|c|c|c|c|c|c|c|c|c|c|c|c|c|c|c|}
\hline & \multicolumn{2}{|c|}{$\begin{array}{l}\text { Persistent D-ER } \\
\text { Users }^{\text {a }}\end{array}$} & \multicolumn{12}{|c|}{ Nonpersistent D-ER Users ${ }^{a}$} \\
\hline & \multicolumn{2}{|c|}{$\begin{array}{l}\text { Overall } \\
\qquad A] \\
\mathbf{n}=719\end{array}$} & \multicolumn{2}{|c|}{$\begin{array}{c}\text { D-ER Supply } \\
<90 \text { Days } \\
{[\mathrm{B}]} \\
\mathbf{n}=125\end{array}$} & $\begin{array}{c}P \\
\text { Value }^{b} \\
{[A]} \\
\text { vs. } \\
\text { [B] }\end{array}$ & \multicolumn{2}{|c|}{$\begin{array}{c}90 \text { Days } \leq \text { D-ER } \\
\text { Supply }<180 \text { Days } \\
{[C]} \\
n=268\end{array}$} & $\begin{array}{c}P \\
\text { Value }^{b} \\
{[A]} \\
\text { vs. } \\
{[C]}\end{array}$ & \multicolumn{2}{|c|}{\begin{tabular}{|}
180 Days $\leq \mathrm{D}-\mathrm{ER}$ \\
Supply $<270$ \\
Days \\
{$[\mathrm{D}]$} \\
$\mathbf{n}=211$
\end{tabular}} & $\begin{array}{c}P \\
\text { Value }^{b} \\
{[A]} \\
\text { vs. } \\
\text { [D] }\end{array}$ & \multicolumn{2}{|c|}{$\begin{array}{c}270 \text { Days } \leq \text { D-ER } \\
\text { Supply }<360 \\
\text { Days } \\
{[\mathrm{E}]} \\
\mathbf{n}=275\end{array}$} & $\begin{array}{c}P \\
\text { Value }^{b} \\
{[\mathrm{~A}]} \\
\text { vs. } \\
\text { [E] }\end{array}$ \\
\hline \multicolumn{15}{|l|}{ Inpatient admissions } \\
\hline $\begin{array}{l}\text { Any all-cause inpatient } \\
\text { admission, } \mathrm{n}(\%)\end{array}$ & 39 & $(5.4)$ & 14 & $(11.2)$ & $0.014^{c}$ & 29 & $(10.8)$ & $0.003 \mathrm{~d}$ & 16 & $(7.6)$ & 0.242 & 23 & $(8.4)$ & 0.086 \\
\hline $\begin{array}{l}\text { Any MS-related inpa- } \\
\text { tient admission, n (\%) }\end{array}$ & 29 & $(4.0)$ & 12 & $(9.6)$ & $0.008^{d}$ & 25 & $(9.3)$ & $0.001^{d}$ & 14 & $(6.6)$ & 0.114 & 21 & $(7.6)$ & $0.020^{c}$ \\
\hline $\begin{array}{l}\text { All-cause inpatient } \\
\text { admissions, mean (SD) }\end{array}$ & 0.06 & $(0.27)$ & 0.17 & $(0.55)$ & $0.012^{c}$ & 0.13 & $(0.40)$ & $0.003^{d}$ & 0.09 & $(0.35)$ & 0.245 & 0.11 & $(0.39)$ & 0.085 \\
\hline $\begin{array}{l}\text { MS-related inpatient } \\
\text { admissions, mean (SD) }\end{array}$ & 0.04 & $(0.22)$ & 0.14 & $(0.52)$ & $0.007 \mathrm{~d}$ & 0.11 & $(0.37)$ & $0.001^{d}$ & 0.08 & $(0.34)$ & 0.111 & 0.09 & $(0.37)$ & $0.019 \mathrm{c}$ \\
\hline \multicolumn{15}{|c|}{ Health care resource expenditures (2014 USD) } \\
\hline $\begin{array}{l}\text { All-cause inpatient } \\
\text { expenditures, } \\
\text { mean (SD) }\end{array}$ & 1,387 & $(8,826)$ & 4,951 & $(28,898)$ & $0.012^{\mathrm{c}}$ & 3,088 & $(12,909)$ & $0.002^{\mathrm{d}}$ & 2,990 & $(15,467)$ & 0.227 & 2,097 & $(8,294)$ & 0.077 \\
\hline $\begin{array}{l}\text { MS-related inpatient } \\
\text { expenditures, } \\
\text { mean (SD) } \\
\end{array}$ & 937 & $(7,401)$ & 1,762 & $(6,729)$ & $0.007 \mathrm{~d}$ & 1,742 & $(7,099)$ & $0.001^{d}$ & 1,699 & $(9,741)$ & 0.113 & 1,249 & $(5,914)$ & $0.020^{c}$ \\
\hline \multicolumn{15}{|c|}{$\begin{array}{l}\text { aPersistent D-ER users were defined as patients with at least } 360 \text { days of D-ER supply. Nonpersistent D-ER users were defined as patients with less than } 360 \text { days of } \\
\text { D-ER supply. }\end{array}$} \\
\hline
\end{tabular}

